\title{
Childhood cancer in the offspring born in 1921-1984 to US radiologic technologists
}

\author{
KJ Johnson', BH Alexander², MM Doody ${ }^{3}$, AJ Sigurdson ${ }^{3}$, MS Linet ${ }^{3}$, LG Spector ${ }^{1,4}$, RW Hoffbeck ${ }^{2}$, SL Simon ${ }^{3}$, \\ RM Weinstock ${ }^{5}$ and JA Ross ${ }^{*, 1,4}$
}

'Department of Pediatrics, Division of Epidemiology/Clinical Research, University of Minnesota, Minneapolis, MN 55455, USA; ${ }^{2}$ Division of Environmental Health Sciences, University of Minnesota, Minneapolis, MN 55455, USA; ${ }^{3}$ Radiation Epidemiology Branch, Division of Cancer Epidemiology and Genetics, National Cancer Institute, National Institutes of Health, Bethesda, MD 20892, USA; ${ }^{4}$ University of Minnesota Cancer Center, Minneapolis, MN 55455, USA; ${ }^{5}$ TI, Rockville, MD 20852, USA

We examined the risk of childhood cancer (<20 years) among 105950 offspring born in 1921 - 1984 to US radiologic technologist (USRT) cohort members. Parental occupational in utero and preconception ionising radiation (IR) testis or ovary doses were estimated from work history data, badge dose data, and literature doses (the latter doses before 1960). Female and male RTs reported a total of $\mathrm{III}$ and 34 haematopoietic malignancies and II 5 and 34 solid tumours, respectively, in their offspring. Hazard ratios (HRs) and 95\% confidence intervals (Cls) were calculated using Cox proportional hazards regression. Leukaemia $(n=63)$ and solid tumours $(n=115)$ in offspring were not associated with maternal in utero or preconception radiation exposure. Risks for lymphoma $(n=44)$ in those with estimated doses of $<0.2,0.2-1.0$, and $>1.0 \mathrm{mGy}$ vs no exposure were non-significantly elevated with HRs of 2.3, 1.8, and 2.7. Paternal preconception exposure to estimated cumulative doses above the 95 th percentile ( $\geqslant 82 \mathrm{mGy}$, $n=6$ cases) was associated with a non-significant risk of childhood cancer of 1.8 ( $95 \% \mathrm{Cl} 0.7-4.6)$. In conclusion, we found no convincing evidence of an increased risk of childhood cancer in the offspring of RTs in association with parental occupational radiation exposure.

British Journal of Cancer (2008) 99, 545-550. doi:I0.1038/sj.bjc.66045I6 www.bjcancer.com

Published online 29 July 2008

(c) 2008 Cancer Research UK

Keywords: radiation; in utero; preconception; malignancy; aetiology; risk factors

Exposure to in utero diagnostic ionising radiation (IR) is generally considered to increase the risk of childhood cancer, including solid and haematological malignancies (Brenner et al, 2003; Wakeford, 2004). Although cohort studies of medical radiation workers have reported increases in the incidence and mortality of skin cancer, breast cancer, and leukaemia, especially in individuals who started working before 1950 when both radiation doses and permitted levels of exposure were higher (Yoshinaga et al, 2004), the risk of cancer in their offspring associated with parental occupational exposure is unclear (Brenner et al, 2003). Radiation could increase offspring cancer risk through germline or in utero somatic mutations (Doll and Wakeford, 1997; UNSCEAR, 2001; Prasad et al, 2004). The only study of childhood cancer incidence in the offspring of medical radiographers found no significant excess (Roman et al, 1996).

The US radiologic technologist (USRT) cohort is one of the largest groups of occupationally exposed medical personnel assembled for study. As 73\% USRT cohort participants are female, both preconception and in utero occupational radiation exposure effects on offspring cancer risk could be studied. In addition, much effort was devoted to reconstructing probable dose levels during

\footnotetext{
*Correspondence: Dr JA Ross, Department of Pediatrics, University of Minnesota, 420 Delaware Street SE, MMC 422 Minneapolis, MN 55455, USA; E-mail: rossx014@umn.edu
}

Received 17 March 2008; revised 23 June 2008; accepted 25 June 2008; published online 29 July 2008 periods when workers were not routinely monitored (Simon et al, 2006), allowing quantitative evaluation of parental exposures. To date, this is the largest study of childhood cancer risk in RT offspring.

\section{METHODS}

The University of Minnesota Institutional Review Board and the United States National Cancer Institute approved all protocols for data use. Complete study details have been described elsewhere (Boice et al, 1992; Doody et al, 1998; Mohan et al, 2002, 2003; Freedman et al, 2003; Sigurdson et al, 2003). Briefly, three questionnaires were mailed to individuals registered with the American Registry of Radiologic Technologists during 1983-89, 1994-98, and 2004-08. The initial questionnaire was sent to 132454 RTs and returned by 90305 of them, a response rate of $68 \%$, whereas $83 \%$ of RTs ( 70859 out of 85372 ) who responded to the first questionnaire returned the second one of which 132118 offspring were enumerated. The following information was reported on the second questionnaire for up to eight of their children: gender; birth year; the occurrence of cancer (no, yes, do not know) and its type (leukaemia, lymphoma, brain, or 'other, specify'; the latter detail was entered into the data file verbatim); diagnosis year; vital status; and death year. We excluded offspring who were born after $1984(n=23123$; the latest year for which estimated doses were available); had missing, incomplete, or 
inconsistent data on birth year, parent birth year, cancer diagnosis year, or death year $(n=2859)$; had reported Down's syndrome ( $n=123)$; or had an 'other cancer' reported as a condition of the skin (other than sarcoma) or the cervix $(n=73)$ occurring during childhood ( $<20$ years), to eliminate potentially benign common conditions of these tissues (e.g., moles and abnormal pap smears). The resultant data set included 81262 and 24678 offspring of female and male RTs, respectively.

Annual occupational radiation doses received by $\mathrm{RT}$ s were estimated as described previously (Simon et al, 2006), using all relevant literature on doses received by RTs (mainly for those working before 1960, when dosimetry was not available), film-badge measurements from a commercial dosimetry provider or military dose registries, dose records provided by employers, and individual work history and protection practices from three cohort surveys. Annual ovary and testes organ dose estimates were used as the best approximations for foetal and germline exposures. The estimated in utero exposure dose was defined as the average of the ovarian doses in the year before and the year of birth, as only the year of birth rather than the date of birth was collected. The estimated preconception dose was calculated as the sum of annual testes or ovary dose estimates up to the year before birth to avoid overlap with the in utero period.

\section{Statistical analyses}

Hazard ratios (HRs) and 95\% confidence intervals (CIs) were calculated by Cox proportional hazards regression (SAS version 9.1; Cary, NC, USA). Person-time was calculated as the interval between the reported birth year and the cancer diagnosis year, death year, the year the child turned age 19, or the year that the second questionnaire was completed, whichever came first. A person-time of 0.5 years was assigned to those who were censored or had an event in their birth year. All regression analyses were stratified by the gender of the parent.

Average cancer incidence rates per million person-years were determined for each age group in years $(0-4,5-9,10-14$, $15-19)$ as the number of events per person-years. The ratio of observed to expected numbers (the standardised incidence ratio (SIR)) was calculated for RT parent and child gender strata for childhood leukaemia, lymphoma, and all sites by applying the sex-specific incidence rates obtained from two registries: (1) Surveillance, Epidemiology, and End Results (SEER) 9 (1973-2004) (SEER, 2007) and (2) Connecticut historical registry (rates available from 1935 to 1999) (SEER, 1999) to the person-time distribution of the offspring cohort (Rothman and Greenland, 1998). For the SEER registry comparison, rates for person-time for years before 1973 were compared to SEER incidence rates for 1975-76, the earliest period with complete data (SEER, 2007). Only subjects whose parents were reported to be white were ncluded due to the small number of other races.

Exposures were modelled as categorical variables with $P$-values for tests for linear trend calculated by inclusion of the continuous measure of dose in regression models. Estimated in utero dose exposures were categorized as follows: $0 \mathrm{mGy}$ (reference), $>0-0.17 \mathrm{mGy}, 0.18-1.0 \mathrm{mGy}$, and 0.01-12.6 mGy. Estimated preconception ovarian and testes dose exposures were categorized according to quartiles: $<0.43 \mathrm{mGy}, 0.43-1.49 \mathrm{mGy}, 1.50-3.57 \mathrm{mGy}$, $>3.57 \mathrm{mGy}$; testes: <0.67, 0.67-4.92, 4.93-15.26, > 15.27) with additional analyses for the offspring of males that divided the fourth quartile at the 95th percentile ( $>81.92 \mathrm{mGy}$ ).

For the offspring of female RTs, results are reported for the following childhood cancer outcomes: (1) leukaemia, (2) lymphoma, (3) solid tumours, and (5) all childhood cancers. Owing to the small number of childhood cancer cases reported by male RTs $(n=68)$, results are given for haematological malignancies (leukaemia and lymphoma), solid tumours, and overall childhood cancers only.

\section{RESULTS}

Characteristics of all RTs and those with eligible children who responded to both the baseline and second questionnaires are provided in Supplementary Table 1 . The majority of RT respondents were female (79\%), born during 1941-1960 (78\%), first employed during 1961-1980 (79\%), and reported having had at least one child $(80 \%)$ with a median of two children.

The characteristics of the offspring are presented in Table 1. The majority of offspring were born between 1960 and 1980 with slightly more male than female offspring, and a more pronounced male excess in cases of leukaemia (58\% male) and lymphoma $(72 \%$ male) (data not shown). The mean estimated in utero and

Table I Characteristics of offspring of members of the USRT cohort $(n=10446 \text { I })^{\text {a }}$

\begin{tabular}{|c|c|c|c|c|c|c|c|c|}
\hline & \multicolumn{8}{|c|}{ Birth year cohort of offspring } \\
\hline & All years & $|92|-1930$ & $|93|-\mid 940$ & $|94|-1950$ & $1951-1960$ & $1961-1970$ & $|97|-1980$ & $1980-1984$ \\
\hline No. of offspring of female RTs & $80396(226)$ & $19(0)$ & $178(0)$ & $1420(2)$ & $9131(36)$ & 23251 (77) & $31232(79)$ & $15165(32)$ \\
\hline$\%$ Male & $51(54)$ & $63(0)$ & $54(0)$ & $52(50)$ & $51(67)$ & $51(49)$ & $5 \mid(53)$ & $51(53)$ \\
\hline Mean in utero dose, mSV & $0.2(0.3)$ & 0 (ND) & 0.7 (ND) & $0.4(0)$ & $0.6(0.7)$ & $0.1(0.1)$ & $0.2(0.3)$ & $0.2(0.1)$ \\
\hline Mean preconception dose, mSV & $3.4(3.4)$ & 0 (ND) & 8.I (ND) & $9.0(0)$ & $7.8(5.4)$ & $4.2(4.1)$ & $1.9(2.5)$ & $2.2(1.5)$ \\
\hline \% Female & $49(46)$ & $37(0)$ & $47(0)$ & $48(50)$ & $49(33)$ & $49(5 \mathrm{I})$ & $49(47)$ & $49(47)$ \\
\hline Mean in utero dose, mSV & $0.2(0.2)$ & 0.7 (ND) & 0.8 (ND) & $0.4(0)$ & $0.6(0.4)$ & $0.1(0.1)$ & $0.2(0.2)$ & $0.2(0.1)$ \\
\hline Mean preconception dose, mSV & $3.5(2.8)$ & 4.9 (ND) & $9.5(\mathrm{ND})$ & $9.3(18.1)$ & $8.1(5.2)$ & $4.2(2.7)$ & $2.0(2.1)$ & $2.2(2.0)$ \\
\hline No. of offspring of male RTs & $24065(68)$ & $0(0)$ & $50(0)$ & $977(3)$ & $3972(13)$ & $6668(23)$ & $8828(23)$ & $3570(6)$ \\
\hline$\%$ Male & $52(60)$ & $0(0)$ & $52(0)$ & $49(67)$ & $52(62)$ & $52(83)$ & $52(43)$ & $52(33)$ \\
\hline Mean preconception dose, mSV & $17(20)$ & - & 42 (ND) & $43(0)$ & $38(40)$ & $18(24)$ & $6.9(3.1)$ & $8.9(14.2)$ \\
\hline$\%$ Female & $48(40)$ & $0(0)$ & $48(0)$ & $51(33)$ & $48(38)$ & $48(17)$ & $48(57)$ & $48(67)$ \\
\hline Mean preconception dose, mSV & $17(13)$ & - & 51 (ND) & $39(58)$ & $37(38)$ & $19(6.9)$ & $7.4(4.0)$ & $8.3(4.3)$ \\
\hline
\end{tabular}

$\mathrm{ND}=$ not determined; USRT $=$ US radiologic technologist. Corresponding case statistics are shown in parentheses. ${ }^{\mathrm{a}} \mathrm{|489}$ subjects had missing data on gender. 
preconception doses in the offspring of both female and male RTs generally decreased over time, declining approximately four- to sixfold from the 1930s through the 1970s and 1980s. Estimated doses were generally low and similar between cases and all subjects.

Approximately $96 \%$ of cases and $95 \%$ of non-cases had parents who reported being white. Cases and non-cases were similar with respect to birth order ( $48 \%$ of cases $v s 46 \%$ of non-cases reported having a birth order of 1). Overall, case parents tended to be younger $(<30$ years) than non-case parents at the time of the offspring's birth (79 vs 73\%) (data not shown).

In total, 294 offspring had reported cancers diagnosed at $<20$ years of age (Table 2). Leukaemia $(n=94)$, lymphoma $(n=61)$, and central nervous system (CNS) tumours $(n=46)$ were the most common cancer types. The peak leukaemia incidence occurred at $<5$ years of age with rates of 72 and 97 cases per million person-years in female and male RT offspring, respectively. Peak lymphoma incidence occurred in older children, with the highest rate being in 15- to 19-year olds. Central nervous system tumour rates did not show marked variation by age in the offspring of female RTs. The pattern for the offspring of male RTs was less consistent, presumably due to the small number of cases $(n=12)$.

No significant increase in risk or dose-response was found for leukaemia, lymphoma, solid tumours, or childhood cancer overall in association with in utero radiation exposure (Table 3). Based on 48 cases of lymphoma, the HR was increased approximately twoto threefold for all dose categories above the reference with no apparent linear trend $(P=0.32)$.

No appreciable increased risk or dose-response was observed between maternal preconception exposure and

Table 2 Age-group-specific childhood cancer rates per million person-years ( $n$ ) reported by USRT cohort members by age group $(n=105940)$

\begin{tabular}{|c|c|c|c|c|c|c|c|c|c|c|}
\hline & \multicolumn{5}{|c|}{ Offspring of female age group (years) } & \multicolumn{5}{|c|}{ Offspring of male age group (years) } \\
\hline & $0-19$ & $0-4$ & $5-9$ & $10-14$ & $15-19$ & $0-19$ & $0-4$ & $5-9$ & $10-14$ & $15-19$ \\
\hline Leukaemia & $33(63)$ & $72(29)$ & $52(21)$ & $19(7)$ & $20(6)$ & $47(21)$ & $97(12)$ & $49(6)$ & $0(0)$ & $31(3)$ \\
\hline Lymphoma & $44(48)$ & $15(6)$ & $22(9)$ & $38(14)$ & $64(19)$ & $29(13)$ & $24(3)$ & $0(0)$ & $44(5)$ & $52(5)$ \\
\hline Solid tumours & $80(115)$ & $116(47)$ & $50(20)$ & $52(17)$ & $97(31)$ & $76(34)$ & $89(11)$ & $25(3)$ & $61(7)$ & $134(13)$ \\
\hline Kidney/Wilms' tumour & $10(14)$ & $25(10)$ & $10(4)$ & $0(0)$ & $0(0)$ & $4(2)$ & $16(2)$ & $0(0)$ & $0(0)$ & $0(0)$ \\
\hline Retinoblastoma & $4(6)$ & $15(6)$ & $0(0)$ & $0(0)$ & $0(0)$ & $11(5)$ & $32(4)$ & $8(1)$ & $0(0)$ & $0(0)$ \\
\hline Thyroid cancer & $4(6)$ & $0(0)$ & $0(0)$ & $0(0)$ & $6(20)$ & $2(1)$ & $0(0)$ & $0(0)$ & $0(0)$ & $10(1)$ \\
\hline Other solid tumours ${ }^{\mathrm{a}}$ & 27 (39) & $17(7)$ & $12(5)$ & $27(10)$ & $57(17)$ & $29(13)$ & $8(1)$ & $8(1)$ & $35(4)$ & $72(7)$ \\
\hline Total childhood cancers & $156(226)$ & $202(82)$ & $125(50)$ & $109(38)$ & $|8|(56)$ & $158(68)$ & $211(26)$ & $74(9)$ & $105(12)$ & $227(21)$ \\
\hline
\end{tabular}

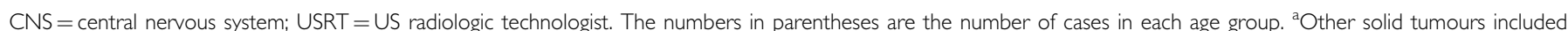
reported offspring cancers: appendix $(n=1)$, bone $(n=4)$, breast $(n=1)$, bladder $(n=1)$, colon $(n=1)$, Ewing's sarcoma $(n=4)$, germ-cell tumours $(n=3)$, leiomyosarcoma $(n=1)$, liver tumours $(n=2)$, lung pulmonary blastoma $(n=1)$, oral $(n=1)$, ovarian $(n=2)$, pancreas $(n=1)$, parotid gland $(n=2)$, primitive neural ectodermal tumours $(n=2)$, rhabdomyosarcoma $(n=5)$, soft tissue sarcoma $(n=2)$, other sarcomas $(n=8)$, stomach $(n=1)$, teratoma $(n=2)$, testicular cancer $(n=4)$, and uterine $(n=3)$,

Table 3 Cox proportional hazards regression modelling of the association between in utero IR exposure and childhood cancer in the offspring of female RTs $(n=8 \mid 262)$

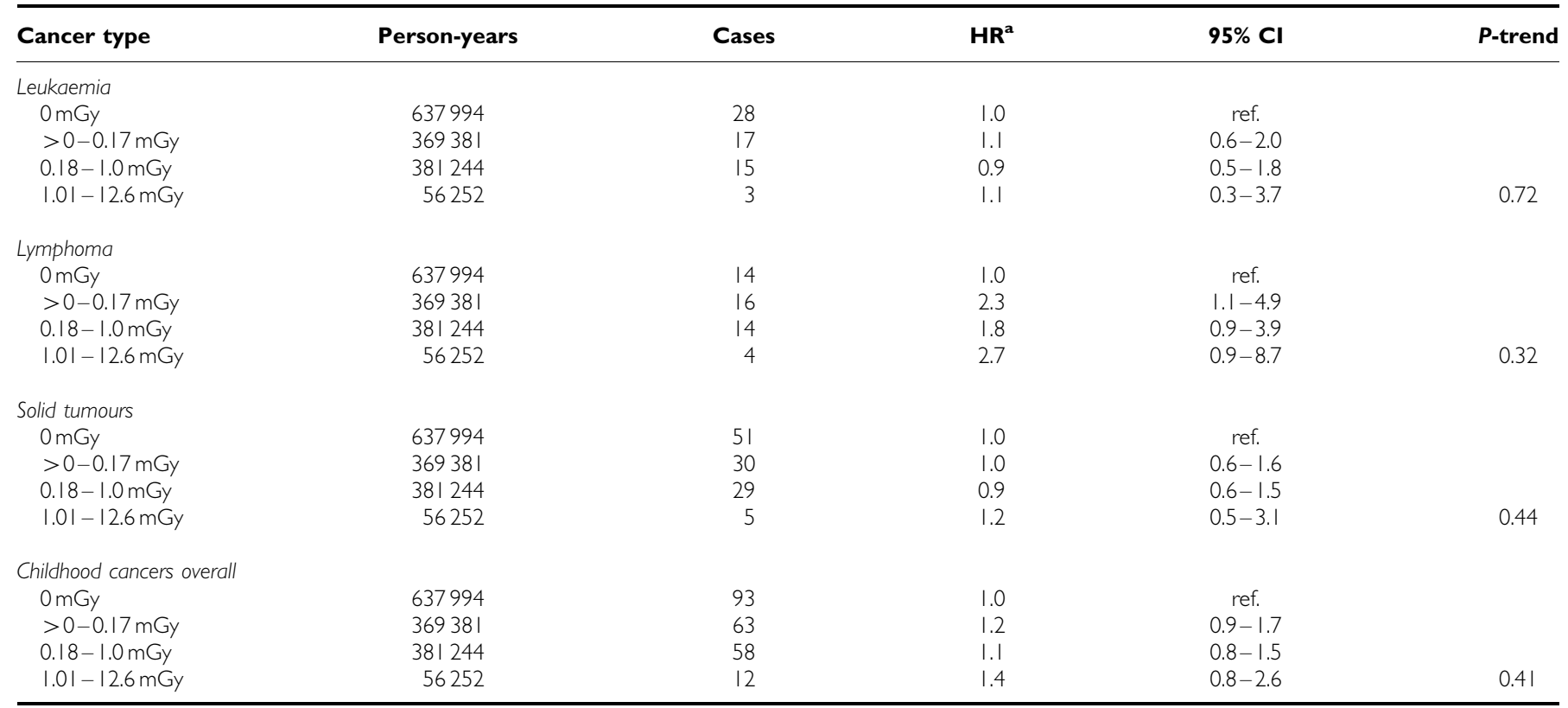

$\mathrm{Cl}=$ confidence interval; $\mathrm{HR}=$ hazard ratio; $\mathrm{IR}=$ ionising radiation; $\mathrm{RT}=$ radiologic technologist. ${ }^{\mathrm{a}}$ Adjusted for birth year. 
Table 4 Standardised incidence ratios comparing childhood cancer incidence rates in the offspring of RTs to SEER and Connecticut registry rates $(n=100|| 5)^{\mathrm{a}}$

\begin{tabular}{|c|c|c|c|c|c|c|c|c|c|c|c|c|}
\hline & \multicolumn{6}{|c|}{ Offspring of females } & \multicolumn{6}{|c|}{ Offspring of males } \\
\hline \multicolumn{13}{|c|}{ SEER registry comparison } \\
\hline Leukaemia & 37 & 30 & $1.2(0.9-1.7)$ & 26 & 24 & $1.1(0.7-1.6)$ & 11 & 9 & $1.3(0.6-2.2)$ & 8 & 7 & $1.2(0.5-2.4)$ \\
\hline Lymphoma & 33 & 20 & $1.7^{b}(1.2-2.4)$ & 14 & 14 & $1.0(0.6-1.7)$ & 10 & 6 & $1.7(0.8-3.1)$ & 3 & 4 & $0.8(0.2-2.2)$ \\
\hline \multicolumn{13}{|c|}{ Connecticut registry comparison } \\
\hline Leukaemia & 37 & 32 & $1.2(0.8-1.6)$ & 26 & 24 & I.I $(0.7-1.6)$ & II & 9 & $1.2(0.6-2.1)$ & 8 & 7 & $1.2(0.5-2.3)$ \\
\hline Lymphoma & 33 & 21 & $1.6^{\mathrm{b}}(1.1-2.2)$ & 14 & 14 & $1.0(0.5-1.7)$ & 10 & 6 & $1.6(0.8-2.9)$ & 3 & 4 & $0.7(0.2-2.1)$ \\
\hline All sites & 120 & 113 & I.I $(0.9-1.3)$ & 101 & 99 & $1.0(0.8-1.2)$ & 41 & 36 & $1.1(0.8-1.5)$ & 24 & 28 & $0.9(0.6-1.3)$ \\
\hline
\end{tabular}

$\mathrm{E}=$ expected; $\mathrm{O}=$ observed; $\mathrm{RT}=$ radiologic technologist; $\mathrm{SEER}=$ Surveillance Epidemiology and End Results. ${ }^{\mathrm{a}}$ Excludes data on 5826 subjects with missing gender or whose parent reported a race other than white. ${ }^{b} P<0.05$.

childhood cancer. The estimated paternal doses above the 95th percentile ( $>82 \mathrm{mGy}$ ) were associated with a non-significant increased risk of $1.8(95 \%$ CI $0.7-4.6)$ relative to the reference group, on the basis of six events (two leukaemia, two lymphoma, one sarcoma, and one oral cancer case) (Supplementary Table 2).

Standardised incidence ratios were calculated for leukaemia, lymphoma, or all reported childhood cancer rates in the offspring of RTs relative to SEER and Connecticut registry rates (Table 4). Cancer incidence was not increased in RT offspring for all sites combined or leukaemia. The incidence of lymphoma was increased in the male offspring of both female and male RTs relative to both population registries with SIRs between 1.6 and 1.7.

\section{DISCUSSION}

Overall, our results do not support an increased risk of childhood cancer in the offspring of RTs associated with occupational IR exposure while in utero or before conception. An increased risk of lymphoma was observed based on a small number of cases but there was no dose-response. Our data do not indicate an association between maternal preconception radiation exposure and offspring childhood cancers. A non-significant increased risk of childhood cancer was associated with paternal preconception exposure only above the 95th percentile ( $>82 \mathrm{mGy}$ ), based on few cases.

In utero exposure to maternal occupational medical radiation did not markedly increase the risk of any of the childhood cancer outcomes examined except lymphoma. A small increase of approximately $40 \%$ in the risk of childhood cancer is thought to be detectable for acute exposure to diagnostic in utero radiation at doses in the range of $10 \mathrm{mGy}$, based on results from case-control studies of subjects born between late 1940s and early 1980s (Doll and Wakeford, 1997). The offspring of RTs in our study were generally exposed to lower doses, with the highest estimated dose for cases being $3.3 \mathrm{mGy}$, for a subject with a reported brain tumour. The estimated mean in utero dose for lymphoma cases was $0.3 \mathrm{mGy}$, which is approximately 10 -fold lower than average annual background radiation exposure (Wakeford, 2004) and, therefore, it is unlikely that maternal occupational radiation exposure explains the increased lymphoma risk.

Consistent with our results, most previous studies have not provided strong support for an association between childhood cancer and parental preconception exposures to either low or high doses of atomic bomb radiation (Izumi et al, 2003a, b), medical or nuclear occupational radiation (Kinlen et al, 1993; McLaughlin et al, 1993; Roman et al, 1993, 1996; Draper et al, 1997; Pobel and Viel, 1997), or therapeutic or diagnostic medical radiation (Kallen et al, 1998; Sankila et al, 1998; Little, 1999; Shu et al, 2002; Patton et al, 2004; Nagarajan and Robison, 2005). A notable exception (Gardner et al, 1990) examined the incidence of leukaemia/non-Hodgkin's lymphoma (LNHL) diagnosed at an age of $<25$ years in individuals living near the Sellafield nuclear facility in England, which included 74 cases of LNHL (14 in the offspring of fathers employed at Sellafield). A significant increased risk of 6.4 for LNHL was reported in association with paternal cumulative preconception radiation dose $>100 \mathrm{mSV}$ on the basis of 4 exposed cases. The case excess was largely confined to the neighbouring village of Seascale (Cumbria, England). Subsequent independent investigations conducted in England, France, Scotland, and Canada have failed to support this association (Kinlen et al, 1993; McLaughlin et al, 1993; Draper et al, 1997; Pobel and Viel, 1997). The alternative hypothesis for Gardner's findings of population mixing (Kinlen, 1988) has been supported by several studies (Little, 1999; McNally and Eden, 2004).

Excess in cases of lymphoma in the male offspring of those exposed to radiation has not been previously reported. No male excess has been reported in association with in utero diagnostic radiation exposure in two of the largest studies: the Oxford Survey of Childhood Cancers (Bithell and Stewart, 1975) and the North-eastern United States study (Monson and MacMahon, 1984), or in the offspring of atomic bomb survivors who were exposed while in utero (Delongchamp et al, 1997).

Our study addresses the important issue of cancer risk in the offspring of medical radiation workers, particularly females, who are exposed to low-level protracted occupational radiation. Prior data comes mainly from studies of cancer risk in offspring of nuclear workers who are predominantly male. However, as with all studies of rare diseases and low-dose exposures, our study has its own limitations. Electronic files of film-badge doses were not routinely available until late 1970s. To estimate these doses, we undertook a comprehensive dose reconstruction that used hundreds of thousands of badge doses from electronic files from 1977 onward, thousands of badge doses from hard copy records for the period 1960-76, and literature-based dose data for the period before 1960 (Simon et al, 2006). This dose reconstruction, although imperfect, is likely to be superior to proxy measures of exposure such as job title. A further limitation is that offspring cancers were ascertained by parent report. Although medical record validation is preferred, the potential success was judged to be prohibitively low, given that many relevant diagnoses occurred 
decades ago and only the parent contact information was available. However, the accuracy of parent-reported offspring cancers is likely to be high based on the level of confirmation of diagnoses in previous analyses (e.g., 98\% of haematopoietic malignancies selfreported by the technologists were confirmed in medical record review) (Linet et al, 2005). Moreover, the absence of an overall increase of cancer compared to rates from two different registries suggests that over-reporting was not a substantial issue with the caveat that conclusions from registry comparisons are limited by differences in geographic coverage and study period. Also, participation bias may have influenced our risk estimates. In our experience, parents of children with cancer are more likely to participate in studies than those with healthy children, thereby tending to produce a greater than expected numbers of cases. However, the overall childhood cancer rates in USRT offspring were similar to the registry rates, suggesting that participation bias did not substantially influence incidence estimates. Participation could bias risk estimates if it was related to both having a child with cancer and exposure level, although we have no data to characterize the direction or magnitude of this potential bias.

\section{REFERENCES}

Bithell JF, Stewart AM (1975) Pre-natal irradiation and childhood malignancy: a review of British data from the Oxford Survey. $\mathrm{Br} J$ Cancer 31: $271-287$

Boice Jr JD, Mandel JS, Doody MM, Yoder RC, McGowan R (1992) A health survey of radiologic technologists. Cancer 69: 586-598

Brenner DJ, Doll R, Goodhead DT, Hall EJ, Land CE, Little JB, Lubin JH, Preston DL, Preston RJ, Puskin JS, Ron E, Sachs RK, Samet JM, Setlow RB, Zaider M (2003) Cancer risks attributable to low doses of ionizing radiation: assessing what we really know. Proc Natl Acad Sci USA 100: $13761-13766$

Delongchamp RR, Mabuchi K, Yoshimoto Y, Preston DL (1997) Cancer mortality among atomic bomb survivors exposed in utero or as young children, October 1950-May 1992. Radiat Res 147: 385-395

Doll R, Wakeford R (1997) Risk of childhood cancer from fetal irradiation. Br J Radiol 70: 130 - 139

Doody MM, Mandel JS, Lubin JH, Boice Jr JD (1998) Mortality among United States radiologic technologists, 1926-90. Cancer Causes Control 9: $67-75$

Draper GJ, Little MP, Sorahan T, Kinlen LJ, Bunch KJ, Conquest AJ, Kendall GM, Kneale GW, Lancashire RJ, Muirhead CR, O'Connor CM, Vincent TJ (1997) Cancer in the offspring of radiation workers: a record linkage study. BMJ 315: $1181-1188$

Freedman DM, Sigurdson A, Rao RS, Hauptmann M, Alexander B, Mohan A, Morin Doody M, Linet MS (2003) Risk of melanoma among radiologic technologists in the United States. Int $J$ Cancer 103: $556-562$

Gardner MJ, Snee MP, Hall AJ, Powell CA, Downes S, Terrell JD (1990) Results of case-control study of leukaemia and lymphoma among young people near Sellafield nuclear plant in West Cumbria. BMJ 300: $423-429$

Izumi S, Koyama K, Soda M, Suyama A (2003a) Cancer incidence in children and young adults did not increase relative to parental exposure to atomic bombs. Br J Cancer 89: 1709-1713

Izumi S, Suyama A, Koyama K (2003b) Radiation-related mortality among offspring of atomic bomb survivors: a half-century of follow-up. Int $J$ Cancer 107: 292-297

Kallen B, Karlsson P, Lundell M, Wallgren A, Holm LE (1998) Outcome of reproduction in women irradiated for skin hemangioma in infancy. Radiat Res 149: $202-208$

Kinlen L (1988) Evidence for an infective cause of childhood leukaemia: comparison of a Scottish new town with nuclear reprocessing sites in Britain. Lancet 2: $1323-1327$

Kinlen LJ, Clarke K, Balkwill A (1993) Paternal preconceptional radiation exposure in the nuclear industry and leukaemia and non-Hodgkin's lymphoma in young people in Scotland. BMJ 306: $1153-1158$

\section{CONCLUSIONS}

Although our sample size is insufficient to detect small increases in risk, we can conclude with certainty that the risk of cancer is not greatly increased in offspring of radiologic technologists.

\section{ACKNOWLEDGEMENTS}

We thank the radiologic technologists who participated in this study; Jeremy Miller of Information Management Services Inc. for his assistance with data analysis; Diane Kampa and Allison Iwan of the University of Minnesota Division of Environmental Health Sciences for their help with data collection. This study was supported by the Children's Cancer Research Fund (Minneapolis, MN, USA); National Institutes of Health (NIH) Grant T32 CA099936; NIH contracts N01-CP-31018 and N01-CP-51016.

Supplementary Information accompanies the paper on British Journal of Cancer website (http://www.nature.com/bjc)

Linet MS, Freedman DM, Mohan AK, Doody MM, Ron E, Mabuchi K, Alexander BH, Sigurdson A, Hauptmann M (2005) Incidence of haematopoietic malignancies in US radiologic technologists. Occup Environ Med 62: $861-867$

Little J (1999) Epidemiology of Childhood Cancer 149th edn, Lyon; Oxford: International Agency for Research on Cancer; Distributed by Oxford University Press

McLaughlin JR, King WD, Anderson TW, Clarke EA, Ashmore JP (1993) Paternal radiation exposure and leukaemia in offspring: the Ontario case-control study. BMJ 307: 959-966

McNally RJ, Eden TO (2004) An infectious aetiology for childhood acute leukaemia: a review of the evidence. Br J Haematol 127: 243-263

Mohan AK, Hauptmann M, Freedman DM, Ron E, Matanoski GM, Lubin JH, Alexander BH, Boice Jr JD, Doody MM, Linet MS (2003) Cancer and other causes of mortality among radiologic technologists in the United States. Int J Cancer 103: 259-267

Mohan AK, Hauptmann M, Linet MS, Ron E, Lubin JH, Freedman DM, Alexander BH, Boice Jr JD, Doody MM, Matanoski GM (2002) Breast cancer mortality among female radiologic technologists in the United States. J Natl Cancer Inst 94: 943 - 948

Monson RR, MacMahon B (1984) Prenatal X-ray exposure and cancer in children. In: Boice J, Fraumeni J (Eds.) Radiation Carcinogenesis: Epidemiology and Biological Significance. Ravan Press, New York, USA, pp. $97-105$

Nagarajan R, Robison LL (2005) Pregnancy outcomes in survivors of childhood cancer. J Natl Cancer Inst Monogr 72-76

Patton T, Olshan AF, Neglia JP, Castleberry RP, Smith J (2004) Parental exposure to medical radiation and neuroblastoma in offspring. Paediatr Perinat Epidemiol 18: $178-185$

Pobel D, Viel J-F (1997) Case-control study of leukaemia among young people near La Hague nuclear reprocessing plant: the environmental hypothesis revisited. BMJ 314: 101

Prasad KN, Cole WC, Hasse GM (2004) Health risks of low dose ionizing radiation in humans: a review. Exp Biol Med (Maywood) 229: $378-382$

Roman E, Doyle P, Ansell P, Bull D, Beral V (1996) Health of children born to medical radiographers. Occup Environ Med 53: 73 - 79

Roman E, Watson A, Beral V, Buckle S, Bull D, Baker K, Ryder H, Barton C (1993) Case-control study of leukaemia and non-Hodgkin's lymphoma among children aged 0-4 years living in West Berkshire and North Hampshire health districts. BMJ 306: $615-621$

Rothman KJ, Greenland S (1998) Modern Epidemiology 2nd edn, pp 234-236. Philadelphia: Lippincott-Raven

Sankila R, Olsen JH, Anderson H, Garwicz S, Glattre E, Hertz H, Langmark F, Lanning M, Moller T, Tulinius H (1998) Risk of cancer among offspring of childhood-cancer survivors. Association of the Nordic 
Cancer Registries and the Nordic Society of Paediatric Haematology and Oncology. N Engl J Med 338: 1339-1344

Shu XO, Potter JD, Linet MS, Severson RK, Han D, Kersey JH, Neglia JP, Trigg ME, Robison LL (2002) Diagnostic X-rays and ultrasound exposure and risk of childhood acute lymphoblastic leukemia by immunophenotype. Cancer Epidemiol Biomarkers Prev 11: 177-185

Sigurdson AJ, Doody MM, Rao RS, Freedman DM, Alexander BH, Hauptmann M, Mohan AK, Yoshinaga S, Hill DA, Tarone R, Mabuchi K, Ron E, Linet MS (2003) Cancer incidence in the US radiologic technologists health study, 1983-1998. Cancer 97: $3080-3089$

Simon SL, Weinstock RM, Doody MM, Neton J, Wenzl T, Stewart P, Mohan AK, Yoder RC, Hauptmann M, Freedman DM, Cardarelli J, Feng HA, Bouville A, Linet M (2006) Estimating historical radiation doses to a cohort of U.S. radiologic technologists. Radiat Res 166: 174-192

Surveillance Epidemiology and End Results (SEER) Program (1999) SEER* Stat database: incidence - Connecticut Historical, Aug 1999 Sub
(1935 - 1997): National Cancer Institute, DCCPS, Surveillance Research Program, Cancer Statistics Branch, 2006

Surveillance, Epidemiology, and End Results (SEER) Program (www.seer. cancer.gov) SEER ${ }^{\star}$ Stat database: incidence - SEER 9 Regs Limited-Use, Nov 2006 Sub (1973 - 2004) - Linked to County Attributes - Total U.S. 1969-2004 Counties, National Cancer Institute, DCCPS, Surveillance Research Program, Cancer Statistics Branch, released April 2007, based on the November 2006 submission

United Nations Scientific Committee on the Effects of Atomic Radiation (2001) Hereditary effects of radiation: UNSCEAR 2001 report to the General Assembly, with scientific annex. New York: United Nations

Wakeford R (2004) The cancer epidemiology of radiation. Oncogene 23: $6404-6428$

Yoshinaga S, Mabuchi K, Sigurdson AJ, Doody MM, Ron E (2004) Cancer risks among radiologists and radiologic technologists: review of epidemiologic studies. Radiology 233: 313-321 